\title{
Use of the Datamyte in analyzing duration of infant visual behaviors
}

\author{
KEITH G. SCOTT \\ Department of Pediatrics, Mailman Center for Child Development \\ University of Miami, Miami, Florida 33152 \\ and \\ WENDY S. MASI \\ Nova University, Fort Lauderdale, Florida 33314
}

\begin{abstract}
The Datamyte 900 is being used to determine the duration of various infant visual behaviors in a study designed to compare the social responses of premature and full-term infants to their mothers and to strangers. The behaviors are recorded initially on video tape and then scored using the Datamyte 900. The data are transmitted to a Modcomp II computer for compression and formatting before being utilized to calculate reliabilities and inferential statistics. A program listing and description is provided, as well as a discussion of user problems.
\end{abstract}

The purpose of our research is to compare the social responses of premature and full-term infants. The responses of four groups of infants (premature males, premature females, full-term females, and full-term males) toward their mothers and toward strangers are first recorded on video tape. The Datamyte 900 is then used to determine the durations of various infant visual (looking) behaviors.

Data are obtained during eight 30 -sec trials. Trials begin as soon as the infant fixates on the social stimulus. On four of the trials the infant interacts with the mother; on the other four trials the infant interacts with a stranger. Data for each subject are recorded on video tape over two complete sessions.

After recording, an observer views the tapes and enters the coded behaviors into the Datamyte by pressing the necessary keys. Dependent measures scored with the Datamyte involve four mutually exclusive infant response categories: duration of visual fixation on the mother or stranger, closing eyes, looking away, and duration to first fixation on a stimulus.

The Datamyte records the duration of events in Inmode 2, one-character autotime and transmits the data in Outmode 1 . This mode records data, line number, and time. A header code is used at the start of each subject's data. This code identifies the subject, the group, and the session number. It is recorded as follows: $H$ subject number (1-32) * 1 or 2 (full-term or premature infant) * 1 or 2 (female or male) * 1 or 2 (session number) $\mathbf{H}$. This code is used only once at the beginning of each subject's data for a particular session. There is also a code to identify the beginning of each trial and to indicate whether on that trial the infant is interacting with the mother or a stranger. This code is as follows: $\mathrm{C}$ trial number (1-8), session number ( 1 or 2 ).
Once the header code and the trial code are recorded, the timing of events begins. Each of the four infant visual (looking) behaviors is assigned a code number. At the beginning of an event, the appropriate number is pressed. This same number is pressed at the end of the event. The computer is programmed to determine the time between two consecutive numbers (e.g., 1-1) by subtracting the total time between the two entries.

If a behavior lasts less than $1 / 100$ of a minute (the minimum interval allowed by the Datamyte), it is recorded as $1 / 100$ of a minute. The end of a trial is determined by the last set of two consecutive numbers received by the computer: No additional identifying information is necessary. Since time is recorded only as the duration of the event (i.e., time between consecutive numbers), timing of behavior can be interrupted at any point within a trial. If the two consecutive numbers are not recorded, an error occurs and the trial is rescored.

Training our observers is not difficult and can be accomplished in less than 1 week. Interobserver reliability data are recorded and analyzed statistically. Relatively few errors are made in the recording of data because of the simplicity of the format. If the observer knows that he made an error, the trial can be rescored. The correction occurs as follows: If two trials of the same number are entered into the Datamyte for a particular subject, the second-trial information supersedes the first set of same-numbered information.

Once data is recorded, and before the Datamyte can be turned off, all data must be transmitted to the computer. Since our data are stored on disk at the computer, any amount of data may be added at a particular time. Unfortunately, it is not always feasible to transmit data to the computer immediately follow- 
ing recording. During this waiting period, any power failure or accidental turn-off of the Datamyte results in data loss. Also, we use "house" power (i.e., ac) for the Datamyte while observing and scoring from the video screen. After the behaviors are recorded and stored in the device, the Datamyte is switched to battery power and transported to the computer. This also increases the chances that data will be lost, either through human error or a weak battery.

In spite of training, observers occasionally substitute
Fs or asterisks for recorded data. These human errors make rescoring necessary. Since data are recorded from video tapes, however, this is not a major problem.

\section{DATA ANALYSES}

For statistical analyses the data are transmitted to disk storage on a Modcomp II $32 \mathrm{~K}$ minicomputer. The computer program is listed in Table 1 and functions as follows.

\section{Table 1}

Program Listing for Compression of Information Received from the Datamyte 900

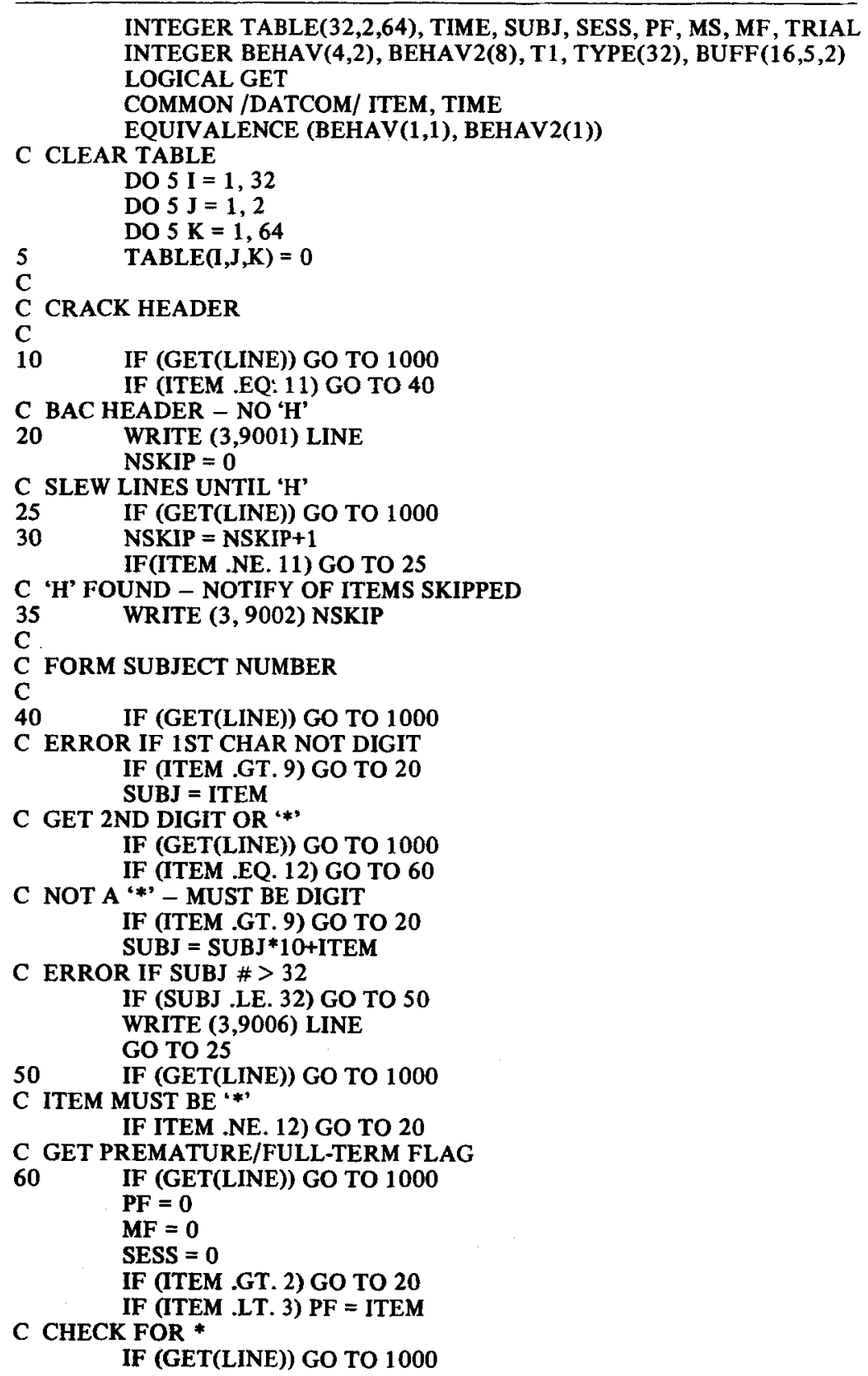


IF (ITEM NE. 12) GO TO 20

C GET MALE/FEMALE FLAG

IF (GET(LINE)) GO TO 1000

IF (ITEM .LT. 3) MF = ITEM

C CHECK FOR '*'

IF (GET(LINE)) GO TO 1000

IF (ITEM .NE. 12) GO TO 20

C GET SESSION NUMBER

IF (GET(LINE)) GO TO 1000

IF (ITEM .LT. 3) SESS = ITEM

C ENSURE THAT WE HAVE MF, PF, SESS IF (SUBJ * SESS * MF * PF .EQ. 0) GO TO 20

C CHECK FOR TRAILING ' $\mathrm{H}$ ' IF (GET(LINE)) GO TO 1000 IF (ITEM .NE. 11) GO TO 20

C WRITE $(3,9501)$ SUBJ, PF, MF, SESS

C CRACK TRIAL HEADER

C

IF (GET(LINE)) GO TO 1000 IF (ITEM .EQ 10) GO TO 90

C NEED A 'C', BUT NONE FORTHCOMING - ERROR

75 WRITE $(3,9003)$ LINE

$77 \quad$ NSKIP $=0$

80 IF (GET(LINE)) GO TO 1000 NSKIP = NSKIP+1

C START OVER WITH NEW HEADER IF ' $H$ ' IF (ITEM .EQ. 11) GO TO 40

C KEEP SLEWING IF NOT ' $C$ ' IF (ITEM .NE. 10) GO TO 80 WRITE $(3,9002)$ NSKIP

C GET TRIAL NUMBER

90 IF (GET(LINE)) GO TO 1000

C TRIAL NUMBER MUST BE $<9$ IF (ITEM .GT. 8) GO TO 75 TRIAL = ITEM

C GET MOTHER/STRANGER FLAG IF (GET(LINE)) GO TO 1000 IF (ITEM .GT. 2) GO TO 75 MS = ITEM WRITE $(3,9501)$ TRIAL, MS

C GET TRIAL START TIME IF (GET(LINE)) GO TO 1000 IF (ITEM .EQ. 5) GO TO 110

C NOTIFY OF NO START TIME

105 WRITE $(3,9004)$ LINE GO TO 77

C COMPUTE TIME TO RECOGNITION

$110 \quad$ T1 $=$ TIME IF (GET(LINE)) GO TO 1000 IF (ITEM .NE. 5) GO TO 105

C

C INITIALIZE TRIAL AREA IN TABLE

C

DO $112 \mathrm{I}=1,8$

112 BEHAV2 $(\mathrm{I})=0$

C ENTER TIM TO REC IN TABLE $\operatorname{BEHAV}(4,1)=$ MAXO(TIME-T1, 1)

C SET TYPE FLAGS IN TABLE $\operatorname{BEHAV}(4,2)=(\mathrm{PF}-1) * 4+(\mathrm{MF}-1) * 2+(\mathrm{MS}-1)$

C GET A BEHAVIOR TYPE

113 IF (GET(LINE)) GO TO 1000

C CHECK BEHAVIOR TYPE FOR VALIDITY
115 IF((ITEM .LT. 1) .OR. (ITEM .GT. 3)) GO TO 140 $\mathrm{LB}=\mathrm{ITEM}$ $\mathrm{T} 1=\mathrm{TIME}$

C GET TERMINATION OF BEHAVIOR IF (GET(LINE)) GO TO 1000 IF (ITEM .EQ. LB) GO TO 130

C BEHAVIOR MISMATCH WRITE $(3,9005)$ LINE GO TO 115

130 BEHAV(ITEM,2) = BEHAV $($ ITEM , 2) +1

C GO LOOK FOR NEXT BEHAVIOR GO TO 113

$\mathrm{C}$

C IF ENTRY WAS C OR H, TRANSFER BEHAVIOR TO TABLE

140 IF ((ITEM .NE. 10) .AND. (ITEM .NE. 11)) GO TO 105 IDX $=($ TRIAL -1$) * 8$ DO $150 \mathrm{I}=1,8$

150 TABLE(SUBJ,SESS,IDX+1) = BEHAV2(I)

IF (ITEM .EQ. 11) GO TO 40

IF (ITEM .EQ. 10) GO TO 90

$\mathrm{C}$

C PRINT TABLE

C

1000 CONTINUE

C FIND NEW TABLE ENTRIES

DO $1020 \mathrm{I}=1,32$

$\operatorname{TYPE}(\mathrm{I})=0$

DO $1010 \mathrm{~J}=1,2$

DO $1010 \mathrm{~K}=8,64,8$

1010

IF $($ TABLE $(\mathrm{I}, \mathrm{J}, \mathrm{K})$.NE. 0) TYPE $(\mathrm{I})=\operatorname{TABLE}(\mathrm{I}, \mathrm{J}, \mathrm{K})$

1020 CONTINUE

DO 2000 MASK $1=1,2$

IF (MASK1 .EQ. 1) WRITE $(3,9101)$

IF (MASK1 .EQ. 2) WRITE $(3,9102)$

DO 1990 MASK2 $=1,2$

IF (MASK2 .EQ. 1) WRITE $(3,9103)$

IF (MASK2 .EQ. 2) WRITE $(3,9104)$

MASK $=($ MASK $1-1) * 4+($ MASK2 -1$) * 2$

DO 1980 SUBJ $=1,32$

$M=$ TYPE(I).AND.MASK

IF (M .NE. MASK) GO TO 1980

WRITE $(3,9105)$

WRITE $(3,9106)$

DO 1050 SESS $=1,2$

DO $1060 \mathrm{MS}=1,2$

IBP $=8 *($ SESS -1$)+4 *(M S-1)$

DO 1070 TRIAL $=1,8$

IT $=$ TRIAL $* 8$

$M=$ TABIE $($ SUBJ, SESS,IT).AND.1

IF (M .NE. (MS-1)) GO TO 1070

$\mathrm{IBP}=\mathrm{IBP}+1$

BUFF(IBP, 1, 1) = TRIAL

IDX $=($ TRIAL -1$) * 8$

DO $1090 \mathrm{I}=1,8$

1090

BEHAV2 (I) = TABLE(SUBJ,SESS,IDX+I)

DO $1100 \mathrm{I}=1,4$

DO $1100 \mathrm{~J}=1,2$

1100 BUFF $($ IBP $, I+1, J)=\operatorname{BEHAV}(I, J)$

1070 CONTINUE

1060 CONTINUE

1050 CONTINUE

WRITE $(3,9107)$ SUBJ, (BUFF $(I, 1,1), I=1,16)$ 


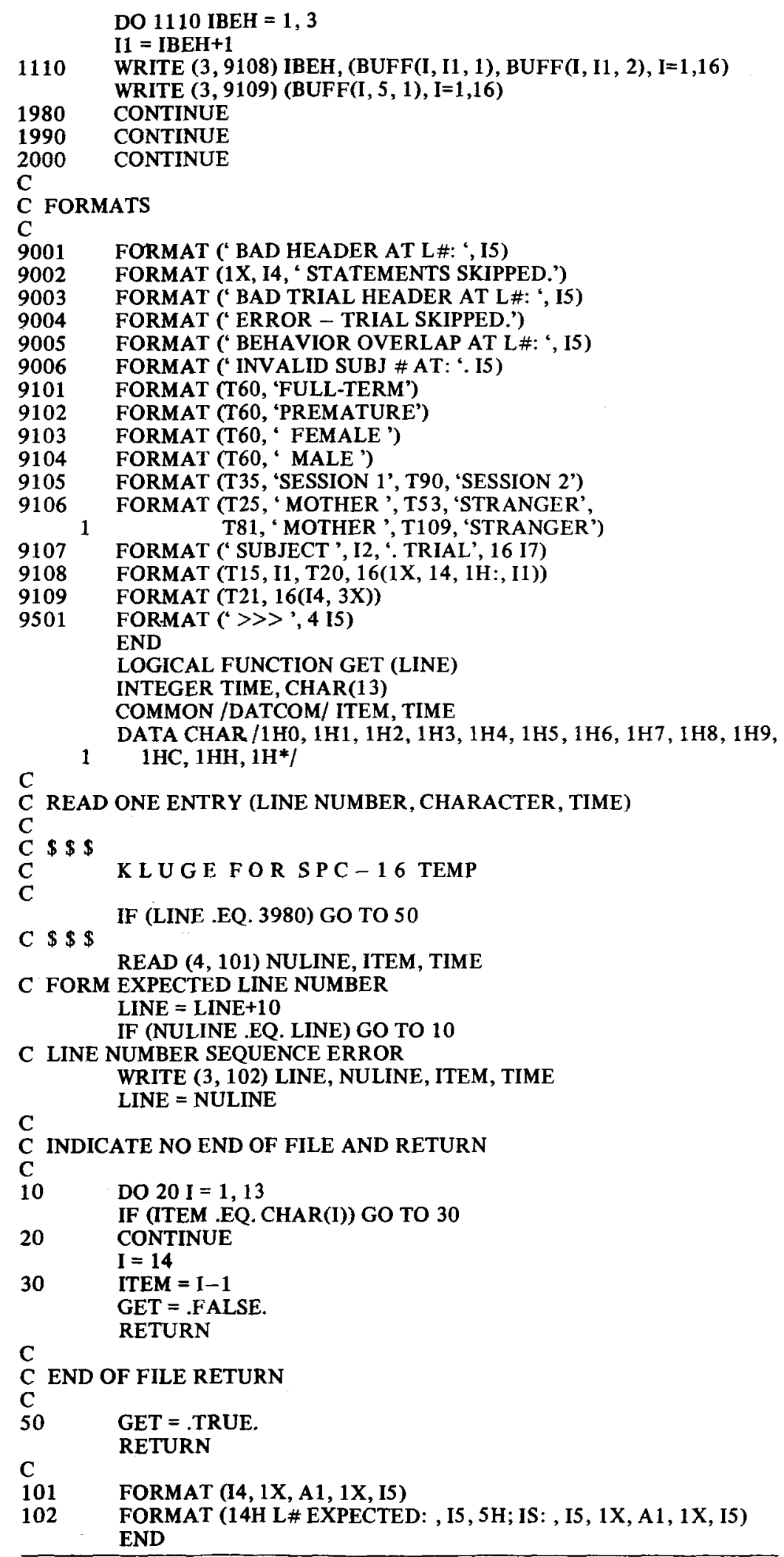

Note-Data are printed out in the format shown in Table 2. 
The program checks first for the header code, which contains identifying information for each subject. A search is made for an $\mathbf{H}$, which signifies the beginning of a header. Next, the program searches for information in the following order: subject number, asterisk, 1 or 2 (signifying premature or full-term), 1 or 2 (signifying male or female), 1 or 2 (signifying session number), and $\mathrm{H}$ (indicating end of header). If the expected information is not received, the line is skipped and an error message, "bad header," is printed out. The program then allows for another header to be entered. If it receives an $\mathrm{H}$, then the header information is re-recorded and previous information dropped. Following reception of a header, the program checks for information identifying the start of a trial. It checks first for a $\mathrm{C}$. If no $\mathrm{C}$ is forthcoming, the line is skipped and an error message is printed. Next, a trial number is checked; if the number is greater than eight (the maximum number of trials), an error is received. The program then searches to determine if the trial is with the mother or a stranger; this is signified by a 1 or 2 .

After receiving trial-identifying information, the timing of behaviors begins. The first behavior computed is time to recognition. The start time at the beginning of a trial is determined by the time recorded when the number " 5 " is received. The program then looks for a second 5 and subtracts the difference between the two numbers. This determines time to recognition. If a trial header is not followed by a 5 , an error message is printed out (error-trial skipped) and all lines are skipped until the start at the next trial is identified by a $C$.

All behaviors within a $30-\mathrm{sec}$ trial are then computed. Three behaviors are recorded: those identified by a 1 (direct fixation), a 2 (looking away), or a 3 (eyes closed). For each defined response a number has been recorded at the beginning and end of the behavior. The program therefore subtracts the time at the first number from the time at the second. If two consecutive numbers are not received, then the program prints out an error message (behavior overlap at line) and the trial is skipped.

The end of a trial is signified by either a $\mathrm{C}$, indicating
Table 2

Format of Data from the Program as Listed in Table 1

Full-Term: Female (or Premature: Male, etc.)

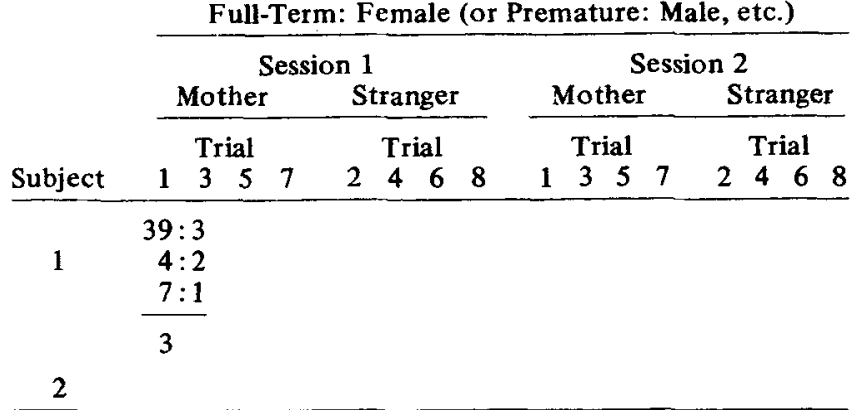

Note-Illustrative data for a single cell are shown. The first pair of numbers $(39: 3)$ represents the time in $1 / 100$ of a minute (30) followed by the number of occurrences of Behavior 1. The next pair of numbers $(4: 2$ and $7: 1)$ are for Behaviors 2 and 3 , respectively. The times sum to 50 , as each trial is 50/100 minute. The final number (3) is the duration of the behavior recorded with a 5 (time to first fixation on the stimulus), again in 1/100-minute units.

a new trial, or an $H$, indicating a new subject. When either a $\mathrm{C}$ or an $\mathrm{H}$ is received, previous trial information is entered into the data entry table and the program recycles. Finally, the information is printed out in a data table in the format shown in Table 2.

Data reduction routines performed by the computer include computing the overall duration of each event per trial and recording the number of times the behavior occurred. The mean time for each behavior across the four trials for the mother and the four trials for the stranger are also computed. Data are analyzed using a four-factor analysis of variance, with two between (birth condition and sex) and two within factors (mother/stranger and session number). The dependent measure for the analysis is behavior $\mathbf{I}$, duration of fixation on the social stimulus. Other behaviors will be used as research progresses.

(Received for publication July 15, 1977; revision accepted August 21, 1977.) 